\title{
1. Co-creation and the city
}

\section{CULTURAL PROGRAMS AND ECONOMIC REGENERATION}

No institutional structure seems stable anymore or at least the façade of stability has collapsed. Moreover, many have come to realize that conventional economic and industrial practices have to change so as to take on a more decentralized, networked and entrepreneurial form, with more transparency, effective regulation and proper accountability. This devolution in action is coupled with a shift toward industries that, up until now, were not even considered at the heart of the industrialized economy or as being highly productive economic sectors but rather, auxiliaries to the mainstream ones. This stereotype is also becoming outdated, as the cultural sector is now expected to provide impetus for growth.

Of course this kind of expectation from the cultural sector is quite high. For, whilst the cultural sector is a vivacious, interesting sector to work in, it is relatively poorer and smaller due to the decrease in financial and institutional assistance it has received from governments and society in general. In recent years, lack of institutional support and the high privatization of the sector has left it smaller than others, with it employing only 3 percent of the workforce in Europe, employing 6.7 million people (European Commission, 2015a) and just over 5.6 percent in the UK (Tera Consultants, 2014). According to the European Commission, cultural and creative industries are responsible for approximately 3.5 percent of all EU products and services annually, but because the cultural sector includes much more than creative industries and jobs, it is probable that the output related to actual creative activity is lower. According to these facts, is it realistic to expect that a sector of small size will be in the position to ignite a new economic boom on a large scale?

This expectation has been raised by policymakers who have adopted the Creative City/Class paradigm initiated by Richard 
Florida $(2002,2004)$ about the use of creativity and culture as a marketing strategy to attract 'creative classes' for industrial recruitment and city development. This is the most popular argument initiated by economists that perceive culture as linked to artistic or creative production (Böhm and Land, 2009; Lazzeretti et al., 2008). However, cultural work has of course value beyond the commercial sphere (as discussed in for example anthropology, ethnology, cultural sciences, political sciences, sociology and geography) because it plays a fundamental part in the creation and mobilization of social and community action to a cause, a change or a way of life. Cultural work contributes to the process of creating essential values, beliefs, morals, ideas, customs and behavior that distinguishes a particular people or society. In a similar vein, the output from cultural industries is affecting attitudes and ways of living, consumption and work so much that it is hard for us to see it as just economic or commercial activity, as is being treated in economics or even in current policymaking. However, we are going to adopt a limited interpretation of culture in this study framed from a management and organization studies perspective, because the motivation and focus in this book is to examine how to manage a public mega-program in the cultureindustry environment, and not to examine what culture is and its effects in general.

This ascent of the creative city as a major business sector, however, was instigated some time ago. The idea came to prominence when Melina Mercouri, actress, political activist and Minister of Culture for Greece, proposed cultural exchange to the European Union in 1983. The underpinning concept was simple: the divide between countries in Europe that culminated in two World Wars was not caused by political and economic differences alone. At the heart of it had been cultural conflict; a clash between social systems and their values. Social systems emerge as diverse and relatively unique, using different values, stereotypes and myths, however, they all internalize discriminating mechanisms to separate themselves from others. Mercouri's proposal was that of cultural exchange, whereby people would get to know their neighbors in the European community and hence, stereotypes and misconceptions would slowly fade. An annual festival of culture would have the explicit purpose to highlight and create awareness about the richness and diversity of European cultures, to bring people from European countries into contact with each other, to promote mutual understanding and to foster a feeling 
of European citizenship (according to the European Commission on ECoCs, 2015a).

The European Union embraced the idea, seeing through that it could facilitate a better movement of capital, labour, goods and services and therefore would provide economic benefits. Experience has shown that such initiatives provide a valuable opportunity to regenerate cities both economically and physically, raise their international profile, improve the identity of their own inhabitants, enhance the vitality to their cultural life and rebrand their international profile (Åkerlund and Müller, 2012). The first program took place in Athens in 1985 (European Commission, 1985). Since then the European Capital of Culture program (hereafter ECoC) has undergone a transformation. Its purpose changed with the economic times and now the focus is on regenerating the local communities economically through an infusion of tourism and other hospitality related business. As a consequence, similar culture programs have emerged, for example the UK City of Culture, with similar expectations. We have to question, however, what level of economic regeneration could actually be achieved and even if it would be sustainable. Some might raise the question of whether this trend is a policy agenda of 'bread and circuses' to distract from the low levels of economic investment in other sectors. For better or for worse, culture is being groomed to become 'big business'.

\section{OUR PROJECT: CO-CREATION AND THE CITY OF UMEA}

This book is about co-creation as practiced within the Umeå ECoC program. We want to develop a framework that explains if and how co-creation can be used as 'strategy-as-practice' (Whittington, 2006; Kornberger and Clegg, 2011; Vaara and Whittington, 2012; Wåhlin et al., 2015) in a beneficial way in the management of a public program like the ECoC, and how the political and economic expectations of city regeneration plans can be met.

The term 'co-creation' means different ideas to different people. We define co-creation as the process within which the main actors in a community (government, academia, business, non-profits and citizens) are engaged in and empowered to negotiate and make decisions, plan and implement in order to tackle systemic change with each of them 
participating from the beginning till the end in this process. Co-creative processes are first and foremost systemic (because they affect every part and level of society); and secondly collaborative, network dependent and horizontally co-ordinated with all the dangers this kind of practice entails. Co-creation is viewed differently in the discourses within the marketing, strategy and innovation management fields where it originated from. Co-creators can be viewed either as proactive actors, or as consumers of products and services that they help to create, and can vary from one individual to entire communities (Bengtsson et al., 2009), or parts of them (Vargo and Lusch, 2004; Lusch and Vargo, 2006; Payne et al., 2008). The most important of these challenges are documented in the fragmented literature on co-creation (Galvagno and Dalli, 2014), however, such a framework is missing from both studies within the policy planning and program management fields although the discourse in several studies has started (Bason, 2010; Dörk and Monteyne, 2011; Kelly et al., 2002; Sørensen and Torfing, 2008; Needham, 2008). Theory and practice still beg for an answer to this question: can we actually include community as a whole into policy and public program schemes and initiatives?

In 2014 the city of Umeå in Sweden became a European Capital of Culture. Umea is a small city of 120,000 inhabitants that at a first glance can pass as just another backward, sleepy provincial town. Umeå was the northernmost ECoC, located about 700 kilometers north of Stockholm and 400 kilometers from the Arctic Pole, with six months of winter, white nights and the Northern Lights. It is located amidst reindeer herds, tall birch forests, and has the only indigenous people of Europe, the Sami, amongst its population. Its two universities fuel the city with diversity by bringing in 39,000 international youth annually, thus building an international reputation. It has a well renowned Design School, a university hospital with progressive medical research and is at the forefront in science pertaining to forestry. Despite its small size, it has an opera, a symphony orchestra and has for decades been a scene for both high and popular-underground grass roots culture work. The city was one of the original places for underground hardcore punk and heavy metal bands in Sweden and it has several large annual festivals, including one of the largest jazz festivals in Sweden. People have an active outdoors lifestyle and get involved in community matters. Umeå is an example that small does not necessarily mean boring. 


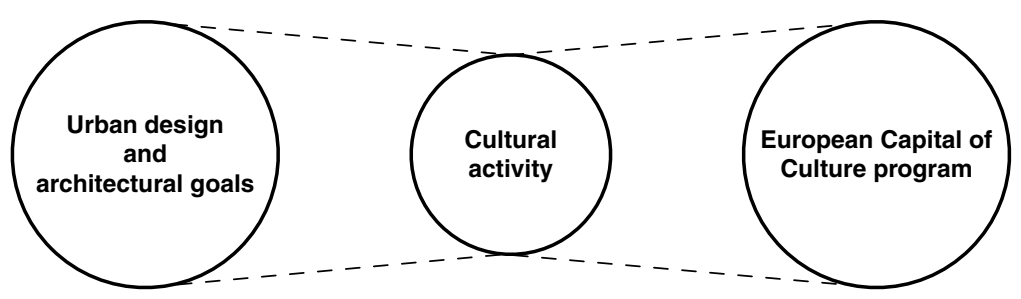

Figure 1.1 Umeå's mixed ECoC program and urban design planning

Umeå's municipality has been working for the past four decades on a city development strategy aiming at a substantial growth in population and public space (Wåhlin et al., 2013a). This vision for urban, social and economic regeneration was prescient, but its formulation into a concrete plan became stagnated, because the local political and financial impetus to forge ahead with it was weak. This, however, changed with the awarding of the ECoC program, which led to the original plan being revisited. In this book, we explain how the program's planning and implementation were fused with the urban plan (Figure 1.1).

Umeå ECoC 2014 was organized as a mega multi-project program, consisting of portfolios of cultural projects organized under a common set of objectives that fulfilled the above mixed strategy of culture and urban planning. Umeå's application to become the European Capital (City of Umeå, 2008, 2009) was successful, to a large extent, due to its unique approach of organizing the project portfolios using the practice of co-creation. Implementing the cultural strategy through co-creation, whilst being a solution for organizing an under-resourced program, brought with it many challenges, not least being the fact that the project implementers were partners and not employees. Consequently, the program office (that played the role of a program management office - PMO) could not exercise control over them as with traditional multi-project initiatives (Näsholm and Blomquist, 2015a). They also had a dilemma in that, on the one hand, they had to be able to fulfil the goals of the European Commission and on the other hand, to fulfil the city's goals of long-term growth in population and increased public space. The 2014 program office put their trust in a number of community actors, sponsors, artists, ambassadors, volunteers, and so on to produce the content of the festival. In this way, a large part of the 
program structure emerged from the community. This level of cocreation was unusual and attracted researchers like us to ask: how was this organized?

Our research project started in 2012 at the start of the implementation of the ECoC 2014 program. Since the organization of the program relied on bottom-up activity coming from the community (Wåhlin et al., 2013b), we had to use a mix of methods involving conventional program analysis with ones which allowed for the examination of emergent action nets and the narratives and stories of the participants. We interviewed, observed and traced the activities of this program for three years with people from the program office, project cultural workers, political decision-making meetings and top sponsors. We made observations, shadowed, interviewed and traced websites and the local press and used the analysis to write this book.

\section{ANALYTIC APPROACH: CO-CREATION STRATEGY AS NARRATIVE PRACTICE WITHIN ACTION NETS}

Above, it was pointed out that the co-creation aspect of the ECoC program meant we had to tackle a new type of obstacle when analysing program planning and implementation: the fact that culturally-driven programs have to plan for emergence, to organize activities that belong to the networks of participants that are not under the control of the predictive powers of the planners (Clegg, 1989). Here is where the strengths of conventional program planning paradigms prove themselves as insufficient to plan for the emergence of program activities. Based on this argument we adopt an unusual analytic approach to study the emergence of the narrative practice from within the local emerging action nets (Figure 1.2).

There were two stages in our analysis. The first stage was to consider how this program was planned. Program planners needed to construct favorable conditions that initiate positive interactions and exchanges between creative workers, and direct them toward program objectives. However, the process of creating the goals and objectives and run both the urban and the cultural programs together was a challenging process itself. Indeed, the 'sweet-spot' of city regeneration occurred when these two planning processes were not in opposition but rather, were aligned. How program planning 


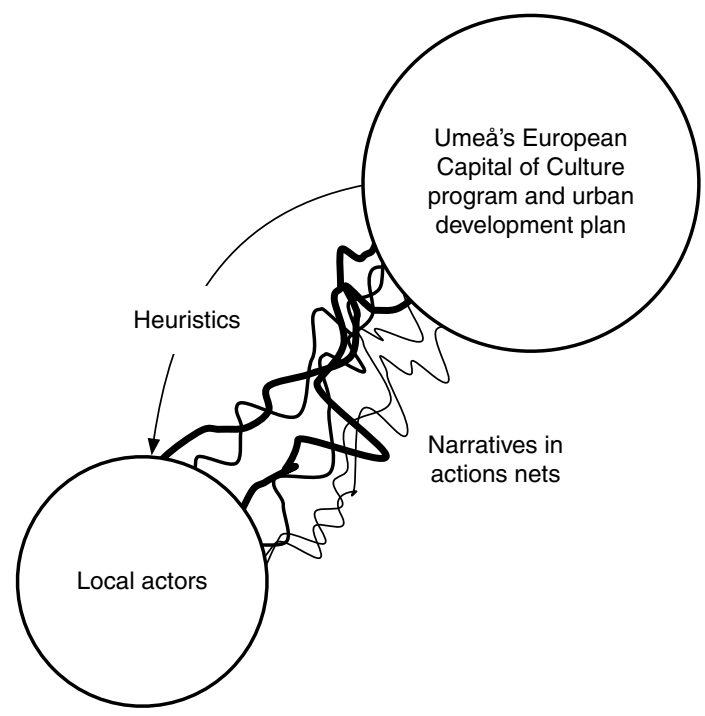

Figure 1.2 Our approach to investigate co-creation through narratives within action nets

and urban design affected each other is one focus of analysis in our work. The first two chapters in Part I are dedicated to investigating this complex planning process and the outcomes. The Umeå ECoC analysis is also a case to see the dynamics of creating a creative and attractive city design for growth (e.g. Florida, 2008; Landry, 2000/2008) as we discuss in Chapter 8.

Our solution to understand the planning process was to apply a 'strategy-as-practice' perspective (Whittington, 2003; Jarzabkowski, 2005; Vaara and Whittington, 2012) through a narrative lens (Fenton and Langley, 2011). The 'strategy-as-practice' perspective helps to explain how strategy-making is enabled or constrained by organizational or social practices (Clegg et al., 2011). The focus is on the process (not on performance) the work (praxis) upon which the program was formulated when in certain times the city's strategic ideas were translated into a master plan by the actors (practitioners). In the master plan we found a set of heuristics that founded project objectives toward program goals and although they were not 'objective' measurements, they were prominent in both feedback and control processes. This program used a set of selection/evaluation 
criteria as heuristics that operationalized the overall strategy and stimulated the urban design of the city plan.

In the second stage in our analysis we investigate the practice of co-creation within the program organization that depends on a fusion of top-down rules and bottom-up action. Therefore our analysis has to overcome the issues of multi-level (macro-micro) analysis to understand how localized and top-down activity combine in an action net, but we have no clear direction from theory regarding what decentralized action looks like. Studies of how emergence happens have detected the usefulness of a decentralized framework for action, but none has provided a case/field study aimed at identifying the characteristics of such a framework. We perceive that action nets are clusters of combined local bottom-up and management top-down activities, and each action net translates and carries a narrative/ translation of the program core values. The narratives from action nets converge to create a master-story. Finally at the core within the link of the interpretation and action is the core value system that happens simultaneously at the micro and the macro levels. Therefore the strategic vision was translated through a narrative plot that is wide enough to integrate self-emerging and diverse 'micro-stories' from the stakeholders into a rhetorically appealing 'master-story' (Fenton and Langley, 2011) that gain direction and momentum whilst a community of cultural practitioners emerges.

Our approach to interpret the emergence of action in nets is to use narrative-interpretivist analysis that can elicit the connections between events or actions in local action nets (Czarniawska, 1997). Therefore our investigation into action nets has a more flat ontology to accommodate the mixture of both micro and macro levels (Seidl and Whittington, 2014) illuminated through narratives.

The interpretation of local action in bottom-up processes depends on the convergence of interpretations of action. This means that we act as we interpret or translate core values within the narratives or short stories we communicate to each other within our networks our interpretations and action have a domino effect within the network, sparking other interpretations and actions that converge and thus create the action net. These translations become the connecting mechanism or 'knotting' between actions (Lindberg and Czarniawska, 2006) which may be examined in the various forms of controlling and organizing (Czarniawska and Sevón, 1996, 2005).

This is the main outline of how we analysed the planning of the 
urban strategy and the organization of the program. However, this research design is more or less diverse, and every empirical chapter adopts a variation, which we describe in the next section.

\section{THE CHAPTERS - AN OUTLINE}

Now we explain how each chapter contributes a piece to the overall portrait of the program with its own version of explaining action nets and the implementation of the strategy. The book has three parts: the first part outlines the planning process and the effects that the urban design and the cultural program have on each other. The second part pieces up the patterns of action based on the narratives in the nets from the people who worked in the program implementation: academia, business, non-profits and citizens. The third part evaluates whether the co-creation experiment was worth it, if it fulfilled the lofty stakeholder expectations that were a very tall order for a temporary endeavor that lasts only a couple of years in preparation and one year of implementation.

\section{Part I: The Planners' View}

The first two chapters in Part I deal with the planning process of the culture program and the urban design.

\section{Chapter 2. The planning process}

We illustrate the planning process during which program planning was done in parallel and at points in collaboration with the urban design development. A stakeholder and time-phase mapping was used because our main focus was to analyse the decision-making on the goals, objectives and main activities of the program and how they were captured in a very prolonged process of negotiation between the stakeholders.

We apply the 'strategy-as-practice' perspective (Vaara and Whittington, 2012) through a narrative lens (Fenton and Langley, 2011) where we analysed the process from which the program was formulated when in certain times the city's strategic ideas were translated into a master plan. In every phase we looked at a point of translation (Czarniawska, 2014a). The point of translation is a key passage where multiple perspectives and tensions shift the narrative 
plot and the values and aims in the narratives. Our analysis of these three translation points demonstrates how people involved perceived the initiative and the role of culture as a development choice.

\section{Chapter 3. The 'cultural turn' in urban design}

Our intent in this chapter was not to analyse Umeå's urban design as a whole but to understand the effects of the cultural program on Umeå's urban design and how they combined together to fulfil the city development plan. This chapter illustrates how the urban design planning was resumed by and became part of the Umeå ECoC program. We first provided a brief historical account of how the Umeå urban design developed until the appearance of the ECoC program, and its development after the Umeå ECoC program. Then we discuss the most important factors for the implementation of the urban design plan: the architectural vision, the projections about the living experience in the public spaces, and schemata about the local culture.

\section{Part II: The View from the Action Nets}

\section{Chapter 4. The organizer's view: exploring emergent project action nets}

This chapter explores the implementation of the ECoC program, but in a different way than the conventional program-portfolio management. In the Umeå ECoC program most of the projects originated from local community activities, they emerged in response to the program calls and they fulfilled a set of goals designed during planning. Our approach was to look how the local activities clustered around narrative themes that formed the whole program. These 'thematic configurations' of local activity are the action nets, and each one of them translates and carries a part of the program story that converge into a larger master-story. In order to find the action nets we look into the narratives and find common patterns of criteria using Qualitative Comparative Analysis (QCA).

\section{Chapter 5. The insider-participant's view: common dualities on urban design and program organization}

This chapter outlines the perceptions from the project co-creators, about how the implementation of both the urban design and the ECoC program ran in parallel, or in some cases ran together. The 
urban plan and the program together made connections between people's action and public space. In the Umeå case the design of space and the ECoC program together created nets that combined both. We used narrative repetition and dualities (Dailey and Browning, 2014; Wåhlin, 2015a) to analyse the course of organizing action and to examine the most influential stories.

\section{Chapter 6. The public's view: analysis of the narratives in the local press}

The purpose of this chapter is to explore how becoming an ECoC is viewed by the local community. We use media-text analysis and compile the dominant narratives into themes in the coverage in one of the local newspapers, and from them we identify the story plots and key themes recurring and construct the main story-themes to understand stakeholder expectations and their perceptions, motives and discourse that follows (Näsholm and Blomquist, 2014). Events are narrated in different ways and communicating narratives is a way to make sense of the past and present and envision the future. A summary is made to how the narrative developed in the years leading up to the implementation.

\section{Chapter 7. Building a milieu for city marketing and branding}

In this chapter we use marketing projects to describe the milieu-network who support the program. The social networks and the broader communications strategy were used not only to promote the local artistic activity but also to attract attention and participation outside the boundaries of the local community. We used social network analysis (SNA) (Marsden, 1990 and Tichy et al., 1979) to analyse the qualitative and interpretive side of networks and combine it with short story vignettes to show the nature of the relationships: whether relationships were formal/informal and/or hierarchical/flat. Relational analysis helps to understand the set of rules holding together the action net.

\section{The Vignette Collection}

This section collates an assortment of short stories divided into two parts. The first part is the 'Space stories', about the public spaces that were planned and constructed because of and with the help of the ECoC program. The 'ECoC stories' are a few examples of projects 
that showcase the distinctive elements of the program. The stories were often cited within the chapters in Part II.

\section{Part III: The Achievement}

\section{Chapter 8. Comparisons with other European Capitals of Culture}

In the final chapters of the book we collate all the previous work together to show the whole picture. What do we learn when we compare the case of Umeå with other ECoCs? We take a look at the four critical themes in co-creation mega-program organization.

In the previous chapters we discussed the planning and implementation of the program in depth from the perspectives of strategy-aspractice. We made many observations and developed the concepts of action nets and narrative infrastructure and how they link to illuminate how Umeå 2014 was planned and implemented by steering action at the community level. In Chapter 8 we summarize the main conclusions and compare them with observations from counterpart ECoCs. This will allow us to pinpoint the effectiveness and efficiency of the Umeå program, identify general trends in ECoC program management and to make informed predictions about ECoCs' legacy and impact for the future of cultural mega-program management.

\section{Chapter 9. Co-creating cities: future challenges}

This book has been about co-creation, as a strategy practiced for the ECoC program 2014. The purpose of this chapter is, first, to build a conceptual framework based on the empirical observations from the Umeå case study. Second, we offer the beginning of a best-practice framework for co-creation practice in cultural mega-programs according to the observations in the case study. We argue that the practice and theory of co-creation in cultural mega-programs is a field that has not yet attracted as much attention as it deserves and that the shortage of academic and best-practice frameworks is holding back the development of this field. During the following short discussion we map the concepts we have observed throughout the chapters (Figure 9.1) and suggest ways to investigate these relationships. Then we construct a best-practice conceptual framework for future practice (Table 9.1). 